\title{
An analysis of patients evacuated by a civilian physician-staffed helicopter from a military base
}

\author{
Youichi Yanagawa ${ }^{1}$, Hiroki Nagasawa1 ${ }^{1}$, Ikuto Takuchi ${ }^{1}$, Shunsuke Madokoro¹, Kei Jitsuiki ${ }^{1}$, \\ Hiromichi Ohsaka ${ }^{1}$, Kouhei Ishikawa ${ }^{1}$, and Kazuhiko Omori ${ }^{1}$
}

${ }^{I}$ Department of Acute Critical Care Medicine, Shizuoka Hospital, Juntendo University, Japan

\begin{abstract}
Objective: We herein report our analysis of patients evacuated by a physician-staffed helicopter (doctor helicopter; $\mathrm{DH}$ ) from a Japan Self Defense Force (JSDF) base.

Methods: From March 2004 to November 2018, a medical chart review was retrospectively performed for all patients who were transported by a DH from the temporary heliport at the JSDF Fuji base. The subjects were divided into two groups: the Before-2013 group ( $\mathrm{n}=6)$ and the After-2013 group $(\mathrm{n}=7)$.

Results: The rate of military-patient involvement and the heart rate of the After-2013 group were greater than those of the-Before 2013 group, and the percutaneous oxygen saturation in the After-2013 group was lower than the Before-2013 group. Furthermore, the Glasgow Coma Scale in the After-2013 group was significantly lower than in the Before-2013 group. The survival rate was not significantly different between the two groups.

Conclusion: Patients transported by DHs in the After-2013 group tended to be in more severe conditions than those transported in the Before-2013 group. This might be due to the fact that over time, the fire department, or JSDF, began to appreciate the useful role played by the DH in life-saving management.
\end{abstract}

Key words: doctor helicopter, military base, evacuation

(J Rural Med 2019; 14(2): 231-235)

\section{Introduction}

Physician-staffed helicopters are called doctor helicopters (DHs) in Japan. By December 2018, 53 DHs had been deployed in 43 prefectures. There were 27,901 dispatches of DHs from April 2017 to March 2018. The crew of these DHs generally consisted of one pilot, one mechanic, one doctor, and one nurse. To perform early medical treatments, indications for dispatch of a $\mathrm{DH}$ are decided upon the receipt of 119 (emergency) calls. It is based on the judgment of the emergency medical technician (EMT) when he or she receives the dispatch request or is put in contact with the patient ${ }^{1)}$. The DH is also used for inter-hospital transporta-

Received: March 4, 2019

Accepted: May 13, 2019

Correspondence: Youichi Yanagawa, Department of Acute Critical Care Medicine, Shizuoka Hospital, Juntendo University, 1129 Nagaoka, Izunokuni City, Shizuoka 410-2295, Japan E-mail: yyanaga@juntendo.ac.jp

This is an open-access article distributed under the terms of the Creative Commons Attribution Non-Commercial No Derivatives (2) $\Theta$ (by-nc-nd) License $<\mathrm{http}: / /$ creativecommons.org/ licenses/by-nc-nd/4.0/>. tion, based on the decision of the physician at the referring hospital. When the DH is dispatched to a scene, it lands at a rendezvous point, such as a schoolyard or an official parking area, where permission has been granted in advance, and the patient is then transported there via ambulance.

The military force in Japan is called the Japan Self Defense Force (JSDF). Military helicopters are typically used for attack, reconnaissance, or transportation of soldiers or supplies, but sometimes they are used for air medical transportation, mainly from remote islands. In such situations, their mission switches to one of a DH. DHs do not fly at night, so air medical transportation at night remains an important mission for the JSDF. While there are many heliports on JSDF bases, JSDF helicopters are parked at specific bases and are dispatched from there on request. In other words, not every JSDF base has such helicopters. The JSDF does not have special helicopters for medical transportation or trained medical staff for helicopter evacuation of severely ill or traumatized patients. In times of peace, severely ill or traumatized military personnel on JSDF bases are generally transported to hospitals via ground ambulances, like lay citizens. The ambulance is allowed to enter the base, pick up the patient and transport him or her to a general hospital. Some heliports in JSDF bases are used as rendezvous points 


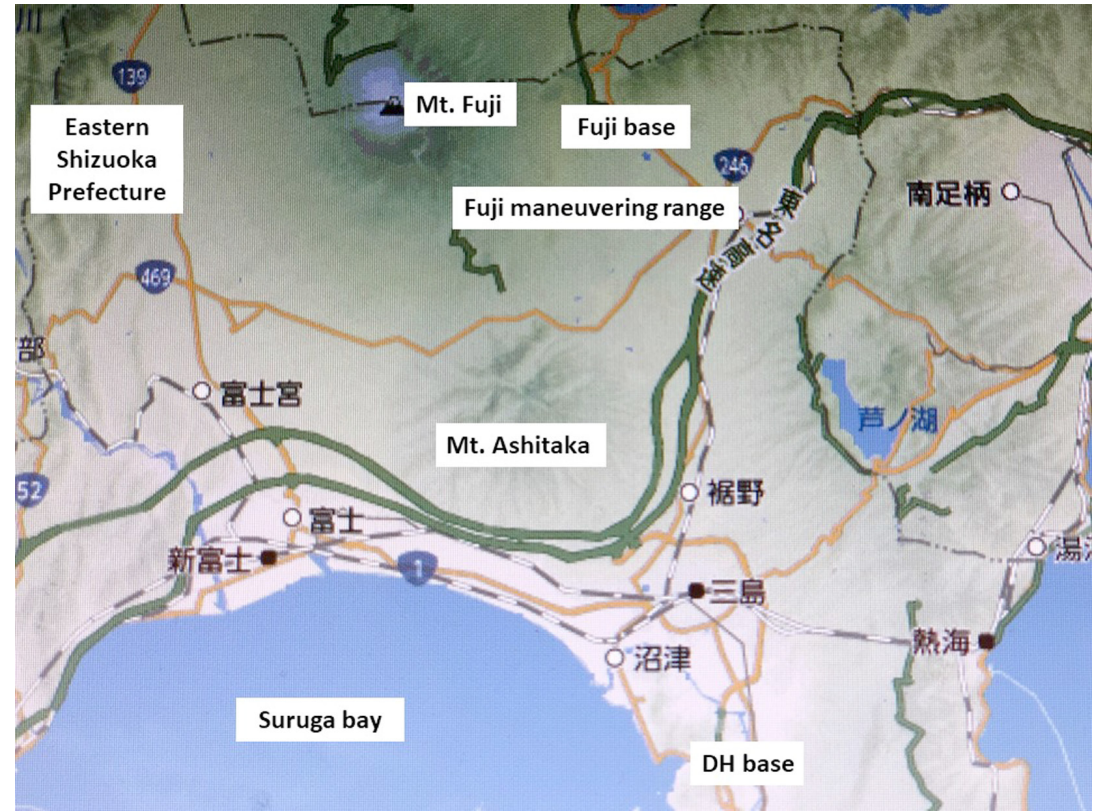

Figure 1 A map of Eastern Shizuoka prefecture.

The doctor helicopter must fly over the Fuji maneuvering range when it flies to Fuji base. Mt: mount; DH: doctor helicopter.

for DHs and ground ambulances to transport severely ill or traumatized citizens or military personnel. There have been no medical reports concerning the evacuation of patients from military bases using non-military helicopters, except for case reports ${ }^{2}$.

We herein report our analysis of patients evacuated via DHs from a JSDF base, which can be used as a reference for military-civilian collaboration in the event of a huge disaster.

\section{Methods}

The protocol of this retrospective study was approved by the review board of Shizuoka Hospital, Juntendo University, and all examinations were conducted in accordance with the standards of good clinical practices and the Declaration of Helsinki.

Shizuoka Hospital, Juntendo University, which is a hospital with 577 beds and a medical emergency center in eastern Shizuoka Prefecture located near Tokyo, serves a population of approximately $1,230,000$. This hospital is also the base of the Eastern Shizuoka DH, which mainly treats patients with severe trauma, acute coronary syndrome, stroke, cardiopulmonary arrest, drowning, decompression sickness, intoxication and unstable vital signs in eastern Shizuoka Prefecture, including rural areas. The Eastern Shizuoka DH service started in March 2004. There are only two acute critical care centers in Eastern Shizuoka. One of them is our institution. Most other hospitals lack emergency physicians. Accordingly, most severely ill or traumatized

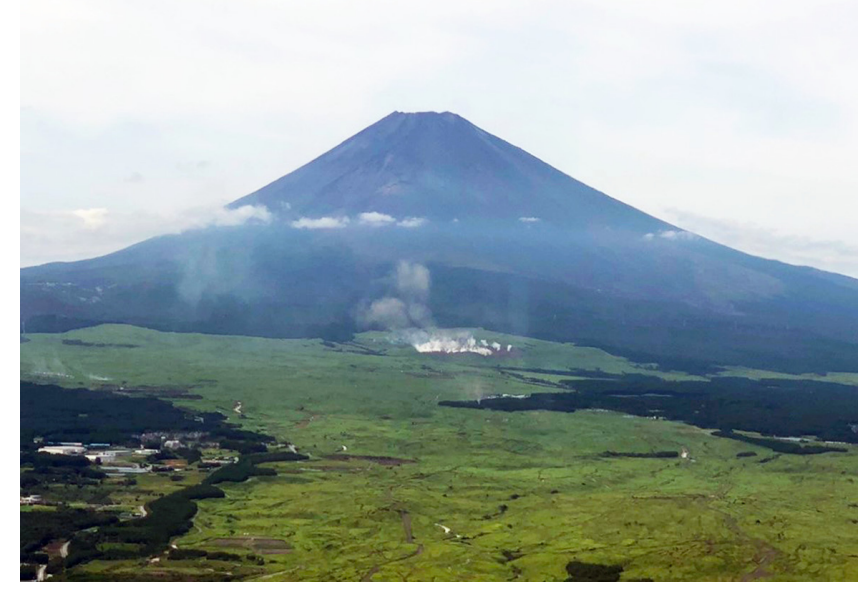

Figure 2 Mount Fuji and Fuji maneuvering range.

Mount Fuji is the highest mountain in Japan $(3,776 \mathrm{~m}$ height). Mountain climbers can summit the peak during the summer season. Fuji maneuvering range is located at the foot of Mount Fuji. The white smoke is from cannonball explosions launched during military training.

patients are transported to our hospital ${ }^{3}$. Eastern Shizuoka includes Mount Fuji, which is the highest mountain in Japan $(3,776 \mathrm{~m}$ height), and the Fuji maneuvering range for the JSDF is located at the foot of the mountain (Figures 1 and 2). To reach the JSDF Fuji base from our hospital, the DH must obtain permission to fly over the Fuji maneuvering range. 


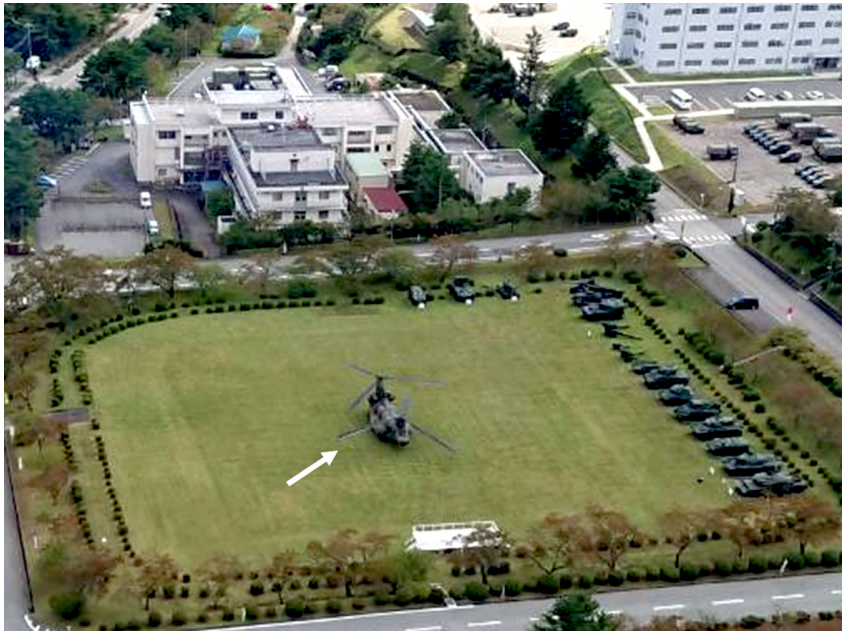

Figure 3 Temporary heliport at the Japan Ground Self Defense Force (JSDF) Fuji base.

There is one temporary heliport at JSDF Fuji base. A CH$47 \mathrm{~J}$ is shown landing on the temporary heliport. The doctor helicopter (DH) can land when permission for use has been granted.

There is one temporary heliport at JSDF Fuji base where the DH can land for emergency medical air evacuation, when permission for use has been granted in advance (Figure 3). In order for the DH to land there, the fire department, which requests the dispatch of the $\mathrm{DH}$, obtains permission from the JSDF Fuji base. After permission has been granted, the staff in the control room of the DH also obtains permission to fly over the Fuji maneuvering range from base operation at the JSDF Fuji base. There are no other helicopters in or near the JSDF Fuji base for air medical evacuation ${ }^{4}$.
From March 2004 to November 2018, a medical chart review was performed retrospectively for all patients who were transported by a DH from the temporary heliport at the JSDF Fuji base, and these patients were included as subjects in the present study. We collected data on each year of dispatch; patient's gender; age; civilian or military status; initial vital signs when the DH staff made contact (Glasgow Coma Scale, systolic blood pressure, heart rate, percutaneous oxygen saturation); treatments provided by the staff of the $\mathrm{DH}$; duration from the 119 call to request of dispatch of the $\mathrm{DH}$, from request of dispatch of the $\mathrm{DH}$ to takeoff, from takeoff to arrival at the scene, scene time, and from request of dispatch of the DH to arrival at the hospital; whether or not cardiopulmonary arrest occurred before the arrival of the DH; and the final outcome (survival or death). The subjects were divided into two groups: the Before-2013 group (dispatch in and before 2013) and the After-2013 group (dispatch after 2013). The variables were compared between the two groups.

Statistical analyses were performed using a $\chi^{2}$, median or paired Student's $t$-test when appropriate. A p-value of $<0.05$ was considered to indicate a statistically significant difference. All of the data are presented as the mean \pm standard deviation.

\section{Results}

During the investigation period, DHs transported a total of 13 patients from the temporary heliport at JSDF Fuji base. There were six patients in the Before-2013 group and seven in the After-2013 group. The background characteristics of the subjects are shown in Table 1.

The results of the analysis between the two groups are

Table 1 Subjects' background characteristics

\begin{tabular}{|c|c|c|c|c|c|c|c|c|c|c|c|c|c|c|c|}
\hline Age & Sex & Military & Diagnosis & GCS & SBP & HR & $\mathrm{SPO}_{2}$ & Treatment & $\begin{array}{c}119 \\
\text { call- } \\
\text { Request }\end{array}$ & $\begin{array}{l}\text { Request- } \\
\text { Take off }\end{array}$ & $\begin{array}{l}\text { Take } \\
\text { off- } \\
\text { Scene }\end{array}$ & $\begin{array}{l}\text { Scene } \\
\text { Time }\end{array}$ & $\begin{array}{l}\text { Request- } \\
\text { Hospital }\end{array}$ & $\mathrm{CPA}$ & Outcome \\
\hline 39 & M & No & Arm amputation & 15 & 141 & 85 & 100 & $\mathrm{O}_{2}$,Div, Monitor, Morphine & 7 & 3 & 14 & 30 & 60 & No & Survival \\
\hline 49 & M & No & Concussion & 15 & 138 & 63 & 100 & $\mathrm{O}_{2}$, Div, Monitor & 18 & 10 & 13 & 20 & 57 & No & Survival \\
\hline 2 & M & No & Burn & 15 & & 91 & 100 & $\mathrm{O}_{2}$, Div, Monitor & 7 & 3 & 13 & 17 & 47 & No & Survival \\
\hline 40 & $\mathrm{~F}$ & No & Abortion & 15 & 95 & 63 & 99 & $\mathrm{O}_{2}$, Div, Monitor & 45 & 3 & 12 & 20 & 52 & No & Survival \\
\hline 41 & M & No & Head injury & 3 & 0 & 0 & 100 & $\mathrm{O}_{2}$, Div, Monitor, Intubation, Adrenaline & 8 & 11 & 15 & 35 & 66 & Yes & Death \\
\hline 30 & M & No & Leg fracture & 15 & 116 & 60 & 100 & Div, Monitor, Echo & 15 & 2 & 17 & 9 & 28 & No & Survival \\
\hline 29 & $\mathrm{~F}$ & No & Mountain sickness & 15 & 102 & 80 & 100 & $\mathrm{O}_{2}$, Div, Monitor, ECG, Echo & 41 & 5 & 11 & 22 & 50 & No & Survival \\
\hline 48 & M & No & Skull fracture & 14 & 142 & 88 & 100 & $\mathrm{O}_{2}$, Div, Monitor, Echo & 8 & 4 & 12 & 11 & 45 & No & Survival \\
\hline 44 & M & No & Finger amputation & 14 & 126 & 124 & 98 & Div, Monitor & 5 & 6 & 12 & 10 & 33 & No & Survival \\
\hline 13 & M & No & Concussion & 14 & 104 & 61 & 100 & $\mathrm{O}_{2}$, Div, Monitor, Echo & 8 & 8 & 12 & 15 & 69 & No & Survival \\
\hline 36 & M & No & Mountain sickness & 14 & 131 & 70 & 98 & $\mathrm{O}_{2}$, Div, Monitor, ECG, Echo & 13 & 22 & 11 & 56 & 121 & No & Survival \\
\hline 51 & M & Yes & Stab wound & 3 & 50 & 132 & 75 & $\begin{array}{l}\mathrm{O}_{2} \text {, Div, Monitor, Dopamine, Transfusion, } \\
\text { Ventilation }\end{array}$ & 0 & 15 & 11 & 27 & 68 & No & Death \\
\hline 45 & M & Yes & CPA & 7 & 60 & 115 & 88 & $\begin{array}{l}\mathrm{O}_{2} \text {, Div, Monitor, Intubation, ECG, Echo, } \\
\text { Diazepam, Midazolam, Vecuronium }\end{array}$ & 11 & 4 & 11 & 3 & 54 & Yes & Survival \\
\hline
\end{tabular}

GCS: Glasgow Coma Scale; SBP: systolic blood pressure; HR: heart rate; $\mathrm{SPO}_{2}$ : percutaneous oxygen saturation; CPA: cardiopulmonary arrest; ECG: 12-lead electrocardiogram; $\mathrm{O}_{2}$ : oxygen; Div: drip intravenous infusion. 
Table 2 Results of the analysis

\begin{tabular}{lccc} 
& & & \\
& Before-2013 & After-2013 & p-value \\
& $\mathrm{n}=6$ & $\mathrm{n}=7$ & $\mathrm{n} . \mathrm{s}$. \\
Age (years) & $33.5 \pm 16.5$ & $38.0 \pm 13.3$ & $\mathrm{n} . \mathrm{s}$. \\
Sex (male/female) & $5 / 1$ & $6 / 1$ & 0.1 \\
Military person (yes/no) & $0 / 6$ & $2 / 5$ & n.s. \\
Trauma (yes/no) & $4 / 2$ & $4 / 3$ & 0.01 \\
Glasgow Coma Scale & $15(12,15)$ & $14(7,14)$ & n.s. \\
Systolic blood pressure (mmHg) & $98.0 \pm 57.8$ & $102.1 \pm 35.3$ & 0.08 \\
Heart rate (beat per minute) & $60.3 \pm 32.2$ & $95.7 \pm 27.8$ & 0.1 \\
percutaneous oxygen saturation (\%) & $99.8 \pm 0.4$ & $94.4 \pm 9.4$ & n.s. \\
Cardiopulmonary arrest (yes/no) & $1 / 5$ & $2 / 5$ & p $<0.01$ \\
Ultrasound (yes/no) & $0 / 6$ & $5 / 7$ & n.s. \\
119 call-Dispatch request (minutes) & $16.6 \pm 14.6$ & $12.1 \pm 13.3$ & 0.1 \\
Dispatch request-Take off (minutes) & $5.3 \pm 4.0$ & $9.1 \pm 6.8$ & p $<0.01$ \\
Take off-Arrival at scene (minutes) & $14.0 \pm 1.7$ & $11.4 \pm 0.5$ & n.s. \\
Dispatch request- Arrival at scene (minutes) & $19.3 \pm 4.3$ & $20.5 \pm 6.6$ & n.s. \\
Scene time (minutes) & $21.8 \pm 9.3$ & $23.4 \pm 15.7$ & n.s. \\
Dispatch-Arrival at hospital (minutes) & $51.6 \pm 13.3$ & $62.8 \pm 28.5$ & n.s. \\
Outcome survival/death & $1 / 5$ & $1 / 6$ & \\
\hline
\end{tabular}

n.s.: not significant.

shown in Table 2 . There were no statistically significant differences in age, sex, contents of the diagnosis (trauma or not), initial systolic blood pressure, rate of cardiac arrest, duration from 119 call to request of dispatch of the $\mathrm{DH}$, scene time, duration from request of dispatch of the DH to arrival at the hospital, or final outcome. The rate of militarypatient involvement, heart rate and duration from request for dispatch of the DH to takeoff to the hospital in the After-2013 group were greater than in the Before-2013 group, and the percutaneous oxygen saturation of the After-2013 group was lower than that of the-Before 2013 group. Furthermore, the Glasgow Coma Scale in the After-2013 group was significantly lower than in the Before-2013 group. The rate of ultrasound scans performed by the staff of the DH at the scene was significantly greater in the After-2013 group than in the Before-2013 group due to the $\mathrm{DH}$ being equipped with a pocket-sized ultrasound machine after 2013.

\section{Discussion}

This is the first report to describe the results of an analysis of patients evacuated by a civilian physician-staffed helicopter from a military base.

In the present study, the patients transported by DHs in the After-2013 group tended to be in more severe conditions than those transported in the Before-2013 group. However, the final outcomes were not significantly different between the two groups. Accordingly, management of DHs may result in obtaining a favorable outcome. In Japan, EMTs cannot secure an airway or infuse drugs for patients not undergoing a cardiopulmonary arrest. However, physicians of
DHs can perform such medical interventions, including lifesaving management, for all patients. This is a great advantage for patients, especially those with unstable vital signs or life-threatening injuries, and it ensures their safe transportation. In addition, fast transportation via helicopter can help ensure a favorable outcome for severely ill or traumatized patients in need of urgent care ${ }^{5-7)}$. The efficacy of the $\mathrm{DH}$ for saving lives has recently been recognized in Japan, and the fire department and JSDF have also recently begun to acknowledge that DHs play a useful role in life-saving management. This may explain the increase in the number of severely ill patients and the number of military persons transported by DHs in the After-2013 group.

The present study revealed that the duration from request of dispatch of the DH to takeoff from the hospital tended to be longer, while that of takeoff from the hospital to arrival at the scene tended to be shorter in the After-2013 group than in the Before-2013 group. The staff of the DH control room tries to adjust the time of the arrival at the rendezvous point based on when the ground ambulance is expected to arrive. This is because the DH has to be guided by staff from the fire department to ensure a safe landing at the rendezvous point. Accordingly, if the $\mathrm{DH}$ arrives at the rendezvous point earlier than the ground ambulance, it must wait in the air until the ground ambulance arrives. It takes a long time for the ground ambulance to enter the JSDF Fuji base. To prevent such waiting in the air, the control room staff carefully control and regulate the dispatch times of DHs. This may explain the time difference mentioned above.

The present study is associated with several limitations, including its retrospective approach, the small number of 
subjects, the lack of data about the number of military persons transported by ground ambulance, and the lack of a comparison with the final outcomes of patients transported via ground ambulance. Future studies involving a larger number of patients are therefore needed to further examine this issue. We hope that this coordinated and combined use of military and civilian resources for life-saving management will help to significantly reduce human suffering in large-scale disasters ${ }^{8,9)}$.

\section{Conclusion}

Patients transported by DHs in the After-2013 group tended to be in more severe conditions than those transported in the Before-2013 group. This might be because the fire department and JSDF have begun to consider that the DH plays a useful role in life-saving management. This coordi- nated and combined use of military and civilian resources for life-saving management will help to significantly reduce human suffering in large-scale disasters.

Conflicts of interest: The authors declare no conflicts of interest in association with this study.

\section{Acknowledgements}

This manuscript received financial support from the Ministry of Education, Culture, Sports, Science and Technology (MEXT)-Supported Program for the Strategic Research Foundation at Private Universities, 2015-2019 concerning [The constitution of total researching system for comprehensive disaster, medical management, corresponding to wide-scale disaster].

\section{References}

1. Omori K, Ohsaka H, Ishikawa K, et al. Introduction of a physician-staffed helicopter emergency medical service in eastern Shizuoka prefecture in Japan. Air Med J 2014; 33: 292-295. [Medline] [CrossRef]

2. Yanagawa Y, Jitsuiki K, Nagasawa H, et al. A smart phone video transmission system for verification of transfusion. Air Med J (in press).

3. Ishikawa $\mathrm{K}$, Omori K, Ohsaka H, et al. A system of delivering medical staff members by helicopter to manage severely wounded patients in an area where medical resources are limited. Acute Med Surg 2016; 4: 89-92. [Medline] [CrossRef]

4. Jitsuiki K, Omori K, Takeuchi I, et al. Multiple patients with heatstroke air evacuated by agreement concerning collaboration. Multiple patients with heatstroke air evacuated by agreement concerning collaboration. Air Med J 2018; 37: 388-391. [Medline] [CrossRef]

5. Andruszkow H, Lefering R, Frink M, et al. Survival benefit of helicopter emergency medical services compared to ground emergency medical services in traumatized patients. Crit Care 2013; 17: R124. [Medline] [CrossRef]

6. Youngquist ST, McIntosh SE, Swanson ER, et al. Air ambulance transport times and advanced cardiac life support interventions during the interfacility transfer of patients with acute ST-segment elevation myocardial infarction. Prehosp Emerg Care 2010; 14: 292-299. [Medline] [CrossRef]

7. Brugger H, Elsensohn F, Syme D, et al. A survey of emergency medical services in mountain areas of Europe and North America: official recommendations of the International Commission for Mountain Emergency Medicine (ICAR Medcom). High Alt Med Biol 2005; 6: 226-237. [Medline] [CrossRef]

8. Motomura T, Hirabayashi A, Matsumoto H, et al. Aeromedical transport operations using helicopters during the 2016 Kumamoto earthquake in Japan. J Nippon Med Sch 2018; 85: 124-130. [Medline] [CrossRef]

9. Matsumoto H, Motomura T, Hara Y, et al. Lessons learned from the aeromedical disaster relief activities following the great East Japan earthquake. Prehosp Disaster Med 2013; 28: 166-169. [Medline] [CrossRef] 